\title{
STEAMPUNK: AS TRANSGRESSÕES TEMPORAIS NEGOCIADAS DE UMA CULTURA RETROFUTURISTA
}

Éverly Pegoraro 
STEAMPUNK: AS TRANSGRESSÕES TEMPORAIS NEGOCIADAS DE UMA CULTURA RETROFUTURISTA ${ }^{1}$

Resumo: O steampunk caracteriza-se como uma cultura urbana juvenil que ressignifica os costumes Vitorianos, permeando-os com discursos tecnológicos e futuristas. A partir dos pressupostos dos Estudos da Cultura Visual, a intenção deste artigo é apontar algumas características da proposta retrofuturista do grupo, argumentando como o steampunk propõe uma visão de mundo peculiar e crítica. Também serão apontadas considerações sobre as influências da cultura da mídia nesse processo.

Palavras chave: Steampunk; Cultura da Mídia; Estudos da Cultura Visual

\section{STEAMPUNK: LAS TRANSGRESIONES TEMPORALES NEGOCIADAS DE UNA CULTURA RETRO-FUTURISTA}

Resumen: El steampunk se caracteriza como una cultura urbana juvenil que resignifica las costumbres victorianas, las mezclando con discursos tecnológicos y futuristas. A partir de los supuestos de los Estudios de la Cultura Visual, la intención de este artículo es señalar características de la propuesta retro-futurista del grupo, argumentando como el steampunk propone una peculiar y crítica visión del mundo. También se indican consideraciones acerca de la influencia de la cultura de la media en este proceso.

Palabras clave: Steampunk; Cultura de la Media; Estudios de la Cultura Visual

\section{STEAMPUNK: THE TEMPORAL TRANSGRESSIONS NEGOTIATED OF A RETRO-FUTURISTIC CULTURE}

Abstract: Steampunk is characterized as a youth urban culture which re-means the Victorian habits, permeating with futuristic and technological speeches. From the assumptions of Visual Culture Studies, the intention of this article is to point out some features of the retro-futuristic proposal of the group, arguing how steampunk proposes a peculiar and critical worldview. It'll also be pointed some considerations about the influence of media culture in this process.

Keywords: Steampunk; Media Culture; Studies of Visual Culture

1 Uma versão prévia deste artigo foi apresentada na Conferencia UC-ICA Latinoamérica, em Santiago, Chile, entre os dias 18 a 20 de outubro de 2012. 


\section{INTRODUÇÃO}

Nosso imaginário é permeado por representações da Era Vitoriana. Conservadorismo e romantismo na contextualização. Maneiras afetadas e roupas extravagantes na estética. Efervescência cultural e grandes invenções no ambiente social e econômico. Os costumes ingleses do século XIX, permeados por discursos tecnológicos e futuristas, têm influenciado uma cultura juvenil que busca ressignificar o contexto desse período em atitudes, posturas e estéticas: os steampunks.

No ambiente criado por seus adeptos, conhecidos como steamers, visualizam-se engrenagens, roupas vitorianas que ganham uma aparência punk; tecnologias atuais remodeladas pelas técnicas antigas. Os steampunks lançam um olhar para o passado impregnado das percepções do presente e, simultaneamente, imaginam um futuro que poderia ter se realizado. Essencialmente, buscam na literatura, no cinema e na produção imagética sobre e do século XIX a visualidade de um passado reinventado no presente, através de diversas performances, numa caracterização retrofuturista.

Este artigo se propõe a discutir a experiência do steampunk, permeando a análise com as concepções de Michel Maffesoli e do ato de ver como ato de perceber o mundo de Maurice Merleau-Ponty. O objetivo é analisar a proposta retrofuturista do grupo a partir de alguns elementos de sua visualidade, apontando como os steamers propõem uma visão de mundo peculiar e crítica. Também serão apontadas considerações pertinentes sobre as influências da cultura da mídia nesse processo.

A análise enquadra-se nos pressupostos dos Estudos da Cultura Visual ${ }^{2}$, os quais buscam entender a própria produção visual como prática social, cultural e política, num desdobramento direto dos Estudos Culturais. A partir da concepção das práticas culturais como práticas de significado, as pesquisas partem das intersecções entre cultura visual, indivíduo e sociedade para discutir as complexidades dos processos de produção visual. Os estudos nessa linha empenham-se, então, em compreender o que as práticas discursivas visuais propiciam em diferentes grupos sociais e como elas constroem e participam da vida das pessoas.

2 A nomenclatura desse campo de estudos diverge entre os seus diversos autores. Neste trabalho, adotar-se-á o nome de Estudos da Cultura Visual, para o campo de estudos, em consonância com a posição de Marquard Smith (2008). 
W.J.T. Mitchell (2003) salienta que a cultura visual é a construção visual do social, não unicamente a construção social do visual. A visão é uma construção cultural, que é aprendida e cultivada, não simplesmente dada pela natureza e, por conseguinte, tem um percurso histórico que precisa ser avaliado. José Luis Brea (2005) corrobora que não há objetos, fenômenos ou meios de visualidade puros, mas atos de ver extremamente complexos que resultam da cristalização e amálgama de um espesso entrelaçamento de dois tipos de forças: os operadores (textuais, mentais, imaginários, sensoriais, mnemônicos, midiáticos, técnicos, burocráticos, institucionais) e os interesses de representação (de raça, gênero, classe, diferença cultural, grupos de crenças e afinidades etc.).

Nesses processos, as visualidades adquirem sentido como um conjunto de relações que combinam informação, imaginação e percepção, de acordo com Nicholas Mirzoeff (2011). Trata-se de uma prática discursiva de rendimento e regulação ao real que tem efeitos materiais. $O$ autor acredita que a visualidade é composta por operações, que podem ser resumidas em três principais. A primeira é classificar pela denominação, categorização e definição, remetendo ao processo de nominação do visível, como conceitua Michel Foucault. Em seguida, a visualidade separa os grupos classificados como um modo de organização social. Por último, ela faz as classificações parecerem certas e estéticas. O autor chama de complexo de visualidade ao conjunto de operações de classificar, separar e estetizar. A denominação de complexo significa a produção de uma série de organizações e processos sociais. (MIRZOEFF, 2011, pp. 3-5)

Os processos de constituição de visualidades envolvem ações de sedução, rejeição e cooptação, desenvolvidos a partir de imagens. Tais ações originamse na experiência visual, que sugere e gera links com o repertório simbólico de cada um. Trata-se de um processo de mapeamento e rastreamento de experiências visuais, permeado por referências ou práticas culturais, que auxiliam na compreensão do mundo social.

Nesta análise, parte-se do pressuposto de que a cultura steampunk propõe uma visualidade específica, formada por um conjunto de elementos que, por sua vez, induz a visibilidades e sociabilidades ressignificadas nos microgrupos que se formam em diferentes lugares, a partir da interferência direta da cultura midiática no processo. Esse conjunto de elementos envolve um repertório de significados imagéticos e textuais. No recorte deste artigo, enfocaremos, a partir de um produto midiático específico do universo steampunk, a revista Vapor Marginal, fragmentos do discurso que permeiam a proposta dessa cultura urbana. 


\section{RETROFUTURISMO E STEAMPUNK}

O steampunk pode ser considerado uma neotribo (MAFFESOLI, 1987). A proposta tem sua "gênese" na ficção científica, como desdobramento do cyberpunk. Os steamers misturam história alternativa e retrofuturismo, nas mais diversas performances e produtos.

$O$ retrofuturismo pode ser entendido como a mistura entre elementos do passado (numa caracterização retrô, obviamente) com tecnologia futurista. Trata-se de explorar os limites e as tensões entre a racionalidade e a alienação provenientes dos avanços da tecnologia.

Para isso, reinventam narrativas históricas tais quais a conhecemos, misturando personagens, fatos e ficções. A ideia é (re)viver ou (re)elaborar situações que existiram no passado, questionando o que teria acontecido caso algumas intervenções técnicas tivessem tomado rumos diferentes e/ou inserindo a tecnologia do "nosso tempo" nesse ambiente passado (FALKSEN, 2011, p. 30). Em outros casos, simplesmente elaboram personagens contextualizados no século XIX, mas mesclados com características futuristas. A fantasia ultrapassou as páginas da literatura e ganhou espaço como cultura urbana. Hoje, o steampunk no Brasil reúne adeptos em vários Estados do país, que se agrupam em "Iojas", apesar de estas não serem relacionadas à venda de produtos.

A junção das palavras steam e punk deve-se ao fato de as histórias se passarem num tempo híbrido entre a Era Vitoriana e um futuro sob a ótica punk. A tecnologia a vapor (steam) é o que inspira grande parte das criações. Uma das justificativas por esse interesse deve-se ao fato de a utilização do vapor ter revolucionado as formas de produção e estar no cerne da Revolução Industrial do século XIX: uma era de grandes mudanças com novos modos de transporte e técnicas produtivas, além das descobertas científicas, medicinais e de armamentos.

\section{O MUNDO SOB A ÓTICA STEAMPUNK}

Para Maurice Merleau-Ponty (1984), a compreensão do ato de ver se dá a partir das relações entre o corpo e a visão. Para ele, o ato de ver é o ato de perceber o mundo, mas numa relação recíproca, já que a percepção é impacto do mundo sobre o indivíduo e, simultaneamente, influência das suas experiências vividas através da corporeidade sobre ele. Dessa confluência dinâmica, não é possível reduzir a visão ao olhar estático, ela acontece no movimento: 
“[...] nossos olhos de carne já são muito mais do que receptores para as luzes, para as cores e para as linhas: são computadores do mundo, que têm o dom do visível como se diz que o homem inspirado tem o dom das línguas" (MERLEAU-PONTY, 1984, p. 280).

Na proposta steampunk, pode-se dizer que há uma forma de olhar o mundo permeada por discursos e representações sobre o passado, que são perpassadas por concepções futuristas, geralmente relacionadas à ciência e tecnologia. Tal forma de olhar o mundo, de senti-lo, como nos ensina Merleau-Ponty, induz a uma dinâmica cultural concretizada em estratégias de sociabilidades e produtos integrantes de um circuito micromídia (THORNTON, 1995). Dessa forma, constata-se que ver não é apenas fruto de uma ação racional e biológica, mas também uma forma de perceber o mundo e ressignificá-lo.

As fontes de inspiração para alimentar o imaginário steampunk caracterizam o centro de constituição de sua visualidade. Percebe-se que há diferentes níveis de influência, desde a literatura, passando pelos produtos da cultura midiática até os próprios gostos individuais. Para alguns, as obras de ficção científica representam o pontapé inicial. As narrativas ficcionais enriquecem a visualidade com suas histórias, personagens e paisagens.

Os steamers visualizam o passado do século XIX como uma época romântica, de grandes aventuras e explorações e apontam, contraditoriamente, fascínio e pessimismo em relação à tecnologia. A produção imagética e as performances estético-visuais steampunks são construídas a partir de um imaginário tecnológico marcado pelas conseqüências do seu desenvolvimento. Nas dinâmicas desse universo, a imagem torna-se uma espécie de elo de sociabilidade, construindo, como sugere Maffesoli (1995), um novo ethos compreendido como uma "ética da estética".

Maffesoli (1995) acredita que todos os domínios da vida social são contaminados pelo jogo das formas, pois tudo aquilo que se cria (seja de que natureza for) só é aceito quando "posto em forma", em outras palavras, quando é disposto em imagem. As formas exercem papel fundamental nos rituais cotidianos. O autor observa que a "colocação em forma" das experiências se investe de temas arcaicos, referências míticas ou imagens dos "bons e velhos tempos". Tais características se enquadram perfeitamente na proposta steampunk.

[...] o mundo imaginal, que está sendo elaborado contemporaneamente, fundamenta-se em um substrato arquetípico. Repete, de 
maneira cíclica, o que se acreditava ultrapassado. É isso que permite falar de maravilhamento, de reencantamento. O imaginário, o simbólico, o onírico, o festivo, são alguns dos parâmetros que exprimem melhor um tal processo. Estão ali os arcaísmos que são reinvestidos e reutilizados pelos diversos meios do desenvolvimento tecnológico. (MAFFESOLI, 1995, p. 147)

Epifanizar objetos e oferecê-los em espetáculos constituem, para o sociólogo, uma parte importante do corpo social, tornando-se elementos de cultura que comportam o estar junto social. Funda-se uma estética do cotidiano que permite experimentar sentimentos, sensações e emoções com os outros - seria uma forma de exprimir sintonia entre objeto e imagem, um aspecto de comunhão entre eles. A participação de cada um nesses rituais cotidianos conduz ao que Maffesoli (1995) conceitua como transcendência imanente, com a dependência de uns em relação aos outros.

Os steampunks realizam um agenciamento da cultura midiática, em parte resultante de suas experiências visuais, promovendo uma transgressão negociada entre passado, presente e futuro. Eles são mais uma manifestação da cultura juvenil típica da "sociedade midiatizada" em que estamos imersos (MORAES, 2006). Através da sua dinâmica cultural, é possível ainda perceber que os vínculos que se estabelecem entre o consumo de bens materiais e simbólicos alimentados pela cultura da mídia que envolve o universo do grupo são reapropriados e ressignificados em contextos locais.

São vários os autores que falam sobre as influências da cultura da mídia (KELLNER, 2001) ou da sociedade midiatizada (MORAES, 2006) sobre as experiências, individuais e coletivas. Denis Moraes (2006) salienta que as relações humanas tendem a "telerrealizar-se" no cenário da midiatização, cujo cenário é caracterizado por interações baseadas em dispositivos teleinformacionais. "As tecnointerações exercem influência marcante nos padrões de sociabilidade e nas percepções dos indivíduos." (MORAES, 2006, p. 36)

Douglas Kellner (2001) mostra que a cultura da mídia, com seus sons, imagens e espetáculos, invade a vida cotidiana, dominando o tempo do lazer, modelando opiniões e comportamentos sociais, fornecendo subsídios para a formação de identidades. "Numa cultura contemporânea dominada pela mídia, os meios dominantes de informação e entretenimento são uma fonte profunda e muitas vezes não percebida de pedagogia cultural: contribuem para nos ensinar como nos comportar e o que pensar e sentir, em que acreditar, o que 
temer e desejar - e o que não." (KELLNER, 2001, p. 10)

Muniz Sodré (2006) afirma que a sociedade contemporânea rege-se pela midiatização, a partir da articulação entre as pautas individuais de conduta e as tecnomediações possibilitadas pelas tecnologias da comunicação. "A midiatização pode ser pensada como um novo bios, uma espécie de quarta esfera existencial, com uma qualificação cultural própria (uma "tecnocultura”), historicamente justificada pelo imperativo de redefinição do espaço público burguês" (SODRÉ, 2006, p. 22). O autor reforça o argumento de que a mídia é estruturadora de percepções e cognições e não apenas de influência normativa. “É que a tecnocultura - essa constituída por mercado e meios de comunicação, o quarto bios - implica uma nova tecnologia perceptiva e mental, portanto, um novo tipo de relacionamento do indivíduo com as referências concretas e com a verdade [...]." (SODRÉ, 2006, p. 23)

Na cultura steampunk, a visualidade extraída da literatura, da cultura da mídia e até mesmo de narrativas históricas resulta em performances que, por sua vez, se traduzem em comportamentos, linguagens, atitudes gestuais e corporais, roupas, acessórios, produções midiáticas (fotonovelas, clipes, games, quadrinhos, músicas etc.) e produções literárias.

\section{DA CULTURA DA MídIA AO CIRCUITO MICROMÍDIA}

Como dito no início deste texto, uma das preocupações dos Estudos da Cultura Visual é justamente compreender as variadas posições do sujeito que emergem através de relações visuais e de produtos provenientes da cultura visual. A seguir, será apresentado um dos produtos do universo steampunk que exemplifica justamente as relações possíveis de serem estabelecidas entre a proposta de tal cultura urbana e suas respectivas reapropriações em produtos integrados ao circuito micromídia.

Cada grupo steampunk aposta em diferenciados produtos midiáticos para dar visibilidade às suas propostas. Neste artigo, serão apresentadas algumas características da Vapor Marginal, uma revista que circula apenas na internet, com o intuito de apontar facetas de um discurso que integra a visualidade steampunk.

A revista teve uma única edição em 2011. Foi editada por Bruno Accioly, um dos fundadores do Conselho Steampunk do Brasil, entidade pioneira que busca divulgar a proposta no país. A junção das duas palavras que compõem o nome 
da revista é relativamente óbvia, pois vapor remete ao período histórico central da proposta steampunk e marginal caracteriza a circulação do produto fora do âmbito mainstream.

O editorial da revista aponta os direcionamentos do produto que pretendia ser periódico. Percebe-se uma certa nostalgia por valores que se acredita mais nobres no passado e perdidos no presente. Diz o texto que a revista é a "manifestação orgânica, caótica e fervilhante do imaginário daqueles que aqui se expressam, em um periódico aberta e intrinsecamente anárquico, mas norteado pelo porpourri [sic] de valores nobres, éticos e morais que talvez tenham existido mais na ficção que na dura realidade" (VAPOR MARGINAL, 2011, p. 2). Em outro trecho, o mesmo editor chama a atenção para a relevância que o século XIX teve para a sociedade e conclama o leitor a despertar "[...] o alter ego SteamPunk de si mesmo, um rebento de uma época que aconteceu mas que foi obliterada da História, mudando nosso passado recente e provocando mudanças que fizeram do mundo o lugar que ele é hoje." (VAPOR MARGINAL, 2011, p. 39)

Se partirmos do conceito de contrato de leitura de Eliseo Verón (2005), podemos identificar o posicionamento do produto perante seu público leitor e como a própria revista identifica e trata aqueles que buscam informação nela. O autor argentino explica que todo suporte impresso contém várias estruturas enunciativas que lhe conferem uma identidade e constituem um contrato de leitura que o suporte propõe ao leitor, o qual se cumpre essencialmente no plano das modalidades do dizer. Dessa forma, cria-se um vínculo entre o suporte e seu leitor. O enunciador de discursos, através do contrato estabelecido podese, por exemplo, propor um lugar para o destinatário do produto: participante da mensagem, expectador passivo, receptor mais ou menos informado, mais ou menos culto, mais ou menos capaz de notar alusões.

O conceito de contrato de leitura implica que o discurso de um suporte de imprensa seja um espaço imaginário onde percursos múltiplos são propostos ao leitor. [...] Ao longo de todo o seu percurso, o leitor reencontra personagens diferentes, que lhe propõem atividades diversas e com os quais ele sente mais ou menos desejo de estabelecer uma relação, conforme a imagem que eles lhes dão, a maneira como o tratam, a distância ou a intimidade que lhe propõem (VERÓN, 2005, p. 236).

Vapor Marginal posiciona-se como "mais um meio de expressão dos fãs" do steampunk, além de acreditar possuir um "potencial pedagógico" num mo- 
mento em que a sociedade brasileira se vê rodeada por "problemas educacionais, éticos e morais" (VAPOR MARGINAL, 2011, pp. 3 e 5). Tais questionamentos ocorrem através das mais diversas manifestações, que aliam prazer e crítica, típicas das culturas urbanas contemporâneas.

[...] a natureza lúdica do Movimento e a diversidade de disciplinas nas quais os Steamers se manifestam funcionam em favor não só da produção, mas da fruição e do resgate cultural, tornando o SteamPunk uma ferramenta poderosa para o ensino e para o aprendizado. (VAPOR MARGINAL, 2011, p. 3)

Como a revista pretendia ser a primeira de um produto periódico, as temáticas abordadas procuraram introduzir aos novatos o tema steampunk, além de mostrar a sua força no Brasil. Ela objetivava ser um "guia" produzido por "singularidades temporais, damas e cavalheiros rasgados do tecido passado do século XIX e cuja Providência Temporal acabou por regurgitar dois séculos depois" (VAPOR MARGINAL, 2011, p. 39). Além de Accioly, outros autores assinam as entrevistas com os precursores dessa cultura no Brasil. O conteúdo é composto por reportagens e artigos opinativos que abordam a moda retrô; a diferença entre cyberpunk e steampunk; as relações e as respectivas influências entre tecnologia e cultura; o fascínio pelo século XIX; o universo literário e a representatividade do livro Steampunk: Histórias de um Passado Extraordinário (2009), o pioneiro do gênero no Brasil; e vários contos steampunks escritos por autores brasileiros. O editorial da revista inclusive explica que a intenção era abrir espaço para escritores, anônimos ou conhecidos, publicarem suas histórias na Vapor Marginal.

\section{CONSIDERAÇÕES FINAIS}

Michel Foucault $(1988 ; 1996)$ mostra que toda prática social tem um caráter discursivo. Nos apontamentos presentes neste texto, é possível comprovar que culturas juvenis contemporâneas, cujas dinâmicas culturais a princípio podem apenas parecer atividades resultantes de hedonismo, consumismo e fruição, na verdade indicam diferentes modos de crítica e agenciamento de espaços, produtos e experiências.

Os produtos do circuito micromídia que se formam a partir de muitas dessas neotribos, como a Vapor Marginal, apostam na criatividade e na imaginação 
como prática social, tal qual Arjun Appadurai (2004) argumenta. Além de abrir espaço para a visibilidade literária de autores que fogem ao circuito mainstream, percebe-se que a preocupação dos steamers vai além dos indícios nostálgicos de uma era passada. Há inquietações sócio-temporais mais profundas, que indicam críticas ao racionalismo e ao consumo exacerbado, como observa-se no fragmento do editorial abaixo:

[No mundo de hoje], inventores são tratados como loucos, substituídos por laboratórios estéreis que vomitam no mercado brinquedos inúteis produzidos por Corporações que objetivam exercer domínio sobre esta nova religião, o Consumo, e doutrinar-nos acerca do que querem que desejemos, nos convencer acerca do que supostamente necessitamos e nos conduzir até acreditarmos que as respostas são mais importantes que as perguntas [...]. (VAPOR MARGINAL, 2011, p. 39)

O "mergulho" no cotidiano de grupos sociais como os steampunks auxilia a compreender as práticas discursivas visuais dos agentes envolvidos nesse processo, bem como a complexidade de suas dinâmicas culturais. Num mundo globalizado e cada vez mais centrado na imagem, analisar a cultura através das experiências visuais é uma forma de procurar entender a importância das práticas imagéticas contemporâneas para a formação dos atos de ver e perceber o mundo.

\section{REFERÊNCIAS}

APPADURAI, Arjun. Dimensões culturais da globalização. A modernidade sem peias. Lisboa: Teorema, 2004.

BREA, José Luis (Ed.). Estudios Visuales. La epistemologia de la visualidad en la era de la globalización. Madrid: Akal Estudios Visuales, 2005.

FALKSEN, G.D. Steampunk 101. In: DONOVAN, Art. The Art of Steampunk. Extraordinary Devices and Ingenious Contraptions from the Leading Artists of the Steampunk Movement. East Petersburg: Fox Chapel Publishing, 2011.

FOUCAULT, Michel. (1971). A Ordem do Discurso. São Paulo: Edições Loyola, 1996.

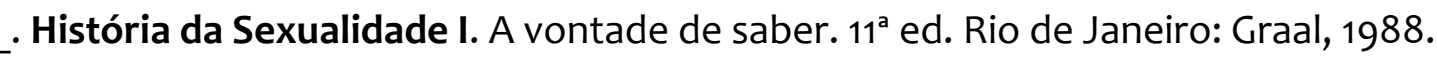

KELLNER, Douglas. A cultura da mídia - estudos culturais: identidade e política entre o moderno e o pós-moderno. Bauru: Edusc, 2001.

MAFFESOLI, Michel. A contemplação do mundo. Porto Alegre: Artes e Ofícios, 1995. 
. O tempo das tribos. O declínio do individualismo nas sociedades de massa. Rio de Janeiro: Forense-Universitária, 1987.

MERLEAU-PONTY, Maurice. O olho e o espírito (1960). In: Textos Escolhidos. $2^{\mathrm{a}}$ Ed. São Paulo: Abril Cultural, 1984.

MIRZOEFF, Nicholas. The right to look. A counterhistory of visuality. Duke University Press, 2011.

MITCHELL, W.J.T . Mostrando el ver: una crítica de la cultura visual. In: Estudios Visuales. Murcia: Centro de Documentación y Estudios Avanzados de Arte Contemporáneo, Noviembre, 2003, pp.17-40. Disponível em http://www.estudiosvisuales.net/revista/index.htm. Último acesso em outubro de 2010.

MORAES, Denis (org.). Sociedade midiatizada. Rio de Janeiro: Mauad X, 2006.

SMITH, Marquard. Visual culture studies. London: Sage Publications, 2008.

SODRÉ, Muniz. Eticidade, campo comunicacional e midiatização. In: MORAES, Denis (org.). Sociedade midiatizada. Rio de Janeiro: Mauad X, 2006, pp. 19-31.

THORNTON, Sarah. Club cultures: music, media and subcultural capital. Cambridge: Polity, 1995.

VAPOR MARGINAL. Especial. Edição Zero, jan. 2011. Disponível em www.vapormarginal. com.br. Último acesso em 13 jan. 2012.

VERÓN, Eliseo. Fragmentos de um tecido. São Leopoldo: Editora Unisinos, 2005.

RECEBIDO EM: 02/11/12

ACEITO PARA PUBLICAÇÃO: 06/11/12

\section{Éverly Pegoraro}

Professora do Departamento de Comunicação da Unicentro, em Guarapuava (PR). Mestre em História Social pela Universidade Federal Fluminense e doutoranda em Comunicação e Cultura pela Universidade Federal do Rio de Janeiro. Autora do livro Dizeres em Confronto: a Revolta dos Posseiros de 1957 na Imprensa Paranaense (2008). 